\title{
Notas latinoamericanas para una filosofía política materialista de los derechos
}

\author{
Sebastián Torres ${ }^{1}$ \\ Universidad Nacional de Córdoba - Argentina
}

Revista Derechos en Acción ISSN 2525-1678/ e-ISSN 2525-1686

Año 5/No 14, Verano 2019-2020 (21 diciembre a 20 marzo), 883-906

DOI: https://doi.org/10.24215/25251678e381

ORCID: https://orcid.org/0000-0002-5067-3751

\section{La cuestión de los derechos}

Desde la segunda mitad del siglo XX la teoría social y la filosofía han desarrollado, desde perspectivas muy diversas, una crítica al sujeto soberano que encuentra en el sujeto de derechos su matriz paradigmática. El supuesto de un individuo libre y consciente, propietario de sí mismo y moralmente autónomo, se encuentra presente como premisa teórica y práctica casi exclusivamente en la esfera del derecho. Esfera que, lejos de ser restricta, se encuentra integrada a la vida social y cultural, a la política y sus instituciones. Último gran pilar de la modernidad occidental, no se mantiene incólume teóricamente, pero se sostiene como única "condición de posibilidad" para pensar un orden social racional, que, por otra parte, parece desmoronarse en procesos multicausales cada vez más acelerados.

Esto es, sin embargo, parte de una evaluación que debiera contrastarse con la persistencia de las luchas por los derechos sostenidas por movimientos sociales y políticos de las más diversas características. Así como, por otra parte, todo un ciclo de gobiernos populares latinoamericanos, los únicos que a inicios

Docente, Universidad Nacional de Córdoba. 
del siglo XXI representaron una alternativa regional concertada ante el avance global del neoliberalismo y el neoconservadurismo, hicieron de los derechos, bajo diferentes figuras -como la "ampliación de derechos", la "restitución de derechos" e incluso la "invención de nuevos derechos"-, un eje fundamental de sus políticas contra-hegemónicas. Un motivo que, en contadas excepciones, fue considerado por la teoría como una dimensión que nos comprometía a una revisión crítica de la larga tradición de cuestionamiento e impugnación a la teoría, el discurso y la política de los derechos.

Esta persistencia de los derechos no asume, sin embargo, un programa de refundación liberal de las democracias contemporáneas: tradición que reclama la exclusividad histórica de este pilar de la teoría social y política. Por el contrario, entre la crisis del sujeto moral y su fundamentación y la crítica sostenida ante el individualismo, emerge la historicidad y politicidad de los derechos, sosteniendo su presencia en diferentes escenas contemporáneas: las ya débiles teorías fundacionalistas son sustituidas por las prácticas históricas concretas. ¿Eso significa que la teoría tiene poco para decir sobre los derechos? ¿Significa que la función crítica de la teoría sólo puede limitarse -y la tarea no es menor- a despejar metafísicas de la naturaleza y la razón? Si los derechos pueden ser explicados mediante las luchas por los derechos, ¿pueden ser considerados solo como un conjunto de reglas específicas, un código de las relaciones de poder entre gobernantes y gobernados, que solo perduran por su relativa eficacia, en las transacciones donde se intercambian bienes por legitimidad? ¿Es posible pensar los derechos desde una perspectiva realista, histórica, a partir de las luchas y las relaciones de poder (Tilly, 2004), sin quedar atrapado en un materialismo reduccionista, que estreche sus posibilidades políticas?

\section{Los derechos como relación}

En el Curso del Colegio de Francia de 1978-1979, Michel Foucault señalará la heterogeneidad entre el sujeto de derecho 
y el homo economicus, no superponibles ni gobernables bajo la misma racionalidad (Foucault, 2007: 334-335) y que, junto a otros análisis del capitalismo contemporáneo, constata el fracaso $-\mathrm{o}$, por lo menos la inactualidad- del liberalismo ante la subjetividad. La crítica al sujeto soberano como sujeto de derecho ya había sido planteada en curso del Colegio de Francia de 1975-1976 y, de diferentes maneras, recorre toda su obra. Menciono a Foucault, entre la extensa serie de críticos al sujeto de derecho, porque incluso en la radicalidad que caracteriza su crítica, también sugirió "encaminarnos hacia un nuevo derecho, que fuera antidisciplinario pero al mismo tiempo estuviera liberado del principio de la soberanía" (Foucault, 2006: 46). Cuál sea ese nuevo derecho, sabemos, no formó parte del plan de sus investigaciones, aunque en una entrevista introduce un concepto que orientará nuestras notas:

Que los derechos individuales habiliten hacer lo que uno quiera, jestá muy bien! Pero si lo que queremos es crear nuevos modos de vida, entonces la cuestión del derecho del individuo no es pertinente. En efecto, vivimos en un mundo legal, social, institucional en el cual las relaciones posibles son extremadamente pocas, extremadamente esquematizadas y extremadamente pobres [...] Más que hacer valer que los individuos tienen derechos fundamentales y naturales, debemos tratar de imaginar y crear un nuevo derecho relacional que permita que todos los tipos posibles de relaciones puedan existir y no sean impedidos, bloqueados o anulados por instituciones relacionalmente empobrecedoras (Foucault, 1994:309)2 .

El concepto de relación, única pista que nos ofrece Foucault, reaparecerá en Etienne Balibar, como parte de su análisis sobre la sexta Tesis sobre Feuerbach de Marx: "Feuerbach resuelve la

\footnotetext{
2 Tomamos la traducción del pasaje, de la tesis doctoral de Julia Monge (2018), "Política de la verdad, filosofía y formas de vida en Foucault: de Nietzsche a un nuevo materialismo", donde desarrolla una lectura materialista de Foucault que permitiría desarrollar, a partir del concepto de "materialismo polémico" que propone, lo que nosotros hemos planteado sólo como una indicación.
} 
esencia religiosa en la esencia humana. Pero la esencia humana no es algo abstracto e inmanente a cada individuo. Es, en su realidad, el conjunto de las relaciones sociales" (Marx, 1992:230231). Balibar encuentra en los términos "conjunto", "relaciones" y "sociales" una equivalencia, orientada al cuestionamiento de las ontologías presuntamente antagónicas que hacen del individuo o el género una realidad primera, un sujeto -el individuo, la humanidad- del cual se predican propiedades esenciales y accidentales.

En efecto, las relaciones de las que hablamos no solo no son nada más que prácticas diferenciadas, acciones singulares de los individuos, ejercidas por unos sobre otros, sino que esta ontología transindividual implica por lo menos una resonancia con enunciados como la Declaración de los Derechos del Hombre y el Ciudadano (con frecuencia considerada muy erróneamente como un texto "individualista") y, más aún, con la práctica de los movimientos revolucionarios: una práctica que jamás opone la realización del individuo a los intereses de la comunidad, que ni siquiera los separa, sino que siempre procura realizarlos uno por el otro. Puesto que si bien es cierto que, en último análisis, sólo los individuos pueden ser portadores de derechos y formular reivindicaciones, la conquista de esos derechos o la liberación (e incluso la insurrección) son no menos necesariamente colectivos (Balibar, 2000:38) ${ }^{3}$.

Abocado a establecer los lineamientos de una ontología relacional no escrita en la obra de Marx, que cuestionaría no solo la concepción economicista y determinista del concepto de relación social, sino también a toda la metafísica precedente,

\footnotetext{
3 El concepto de transindividualidad -en el que no nos detendremos aquí- es recuperado por Balibar (2009) a partir de una lectura de Spinoza leído bajo esta categoría tomada de Gilber Simondon. Para la discusión sobre las categorías modernas, provenientes del jusnaturalismo, la recuperación de la filosofía de Spinoza será central. Así como Balibar, Antonio Negri rescatará el concepto spinoziano de multitud, orientado también a una crítica del individualismo y el universalismo (1993 y 2000). Una fundamental lectura crítica a través de Spinoza, para pensar Latinoamérica, es realizada por Abdo Ferez (2013).
} 
Balibar solo sugiere una resonancia, que conduce directamente a la Declaración de los Derechos de 1789, recusando su carácter puramente "individualista". Esta dirección que le imprime a las posibilidades teóricas y políticas del concepto de relación, para Balibar no supone apartarse totalmente de la crítica a la Declaración de Derechos realizada por Marx en La cuestión judía (aunque la crítica a su interpretación individualista atañe también a Marx), todavía una referencia fundamental para Balibar (2014), como para gran parte de la crítica contemporánea ${ }^{4}$. Lo que permite revisar es el supuesto corolario que indicaría abandonar (o superar) la política de los derechos. Abandono que, por otra parte, se ha desprendido -y no sin razones, como sucede con Marx- también de la crítica foucaultiana.

Si Foucault sugería pensar otro derecho en términos relacionales, Balibar nos dice que pensar un derecho relacional es también, pensar de otro modo los derechos y sus historias. La posible divergencia ${ }^{5}$, sin embargo, no impide notar que, en ambas indicaciones, el concepto de relación es tanto un concepto crítico como positivo.

El concepto de relación remite, en primera instancia, al primado de la relación por sobre los términos de la relación, esto significa que no son las cualidades esenciales de los términos los que determinar cuáles relaciones son naturales y cuáles son accidentales, sino que el primado de la relación determina los términos de la relación, derivándolos de ella. Ni el individuo ni el género son esencias originarias, sino abstracciones resultado de determinadas relaciones (como lo indicaría la 6ta tesis marxiana). Determinación que no es trascendental sino inmanente, constituida por prácticas concretas y, por tanto, plurales (por lo que debiéramos hablar de relaciones, en plural). Es en y por ese

\footnotetext{
4 Para mencionar dos de las más recientes relecturas de Marx a propósito de la crítica contemporánea de los derechos, se puede ver Žižek (2011) y Brown (2007).

5 Para una relación entre Foucault y Balibar, también a propósito de Marx, remito nuevamente a Monge (2018).
} 
tejido de relaciones que nos individuamos y se producen determinadas estructuras (relaciones que se reproducen y duran en el tiempo). Como lo señala Morfino (2010 y 2014) -cuyos trabajos representan el desarrollo más sistemático y original realizado sobre este concepto- hablar de una ontología relacional sería un oxímoron, dado que el término relación sería directamente opuesto a los de sustancia o esencia, que clásicamente han definido a la ontología; pero es esta contradicción, entre lo necesario y lo contingente, entre lo inmutable y lo cambiante, entre lo universal y lo singular, se encuentra todo el potencial teórico del concepto.

¿Pero, es posible pensar los derechos a partir de esta ontología relacional, como lo sugiere Balibar? La ganancia crítica, que permite cuestionar al sujeto soberano podría, sin embargo, pasar por alto una dimensión constitutiva de los derechos: la diferencia entre hecho y derecho. Esto no supone, como veremos, asumir que los derechos posean necesariamente una naturaleza ideal o racional normativa: como sostiene Rinesi, se reclama un derecho cuando de hecho no se lo tiene (2015) y es ese modo del (no)ser de los derechos lo que los hace irreductibles a un hecho o una realidad, expresando una tensión entre hecho y derecho que no se corresponde plenamente con la distinción entre ser y deber ser. Por lo que, una teoría relacional de los derechos, que los reduzca a las relaciones fácticas que constituyen a los individuos, podría perder esa dimensión política que opera entre lo real y lo simbólico, y que es constitutiva de su práctica. $\mathrm{O}$, en otros términos, el carácter relacional de los derechos no puede ser reductible a las "relaciones sociales" sin más y a una definición unívoca de la práctica.

Por lo demás, el alcance de esta perspectiva filosófica para interrogar los dualismos que están supuestos en la bifurcación entre ciencias sociales descriptivas y ciencias normativas (como la ética y el derecho), aunque no será directamente tematizado, quedará entre líneas, como parte de los efectos críticos de nuestro abordaje. 


\section{Lo real, lo simbólico, lo relacional: indeterminación y pluralidad}

"Derechos del Hombre y política" de Claude Lefort es una de las más influyentes intervenciones, que abrieron una vía para pensar la dimensión política y democrática de los derechos, a partir de una relectura de la Declaración de los derechos del hombre y el ciudadano de 1789 ( $\sin$ duda, antecedente de la referencia de Balibar).

A partir de una crítica a la crítica de Marx en La cuestión judía, donde los derechos serían reducidos a una estructura ideológica de alienación que ocultaría las relaciones sociales capitalistas individualistas, pero también -y por extensión- a la dominante lectura liberal, que funda los derechos en una naturaleza humana (individual o genérica), esto es, a dos formas a partir de las cuales los derechos son remitidos a un factum, Lefort encuentra en la Declaración de derechos uno de los momentos fundamentales de lo que denomina la indeterminación democrática. Caracterización de la "revolución política moderna", en donde se produce una disociación entre las instancias del poder, la ley y el saber, donde el derecho representa una exterioridad no subsumible al poder, consecuencia de que ningún término posee un punto de arraigo cierto e indiscutible. La Declaración de los derechos del hombre y del ciudadano representaría la concreción histórica de esta indeterminación. Si bien en los derechos el hombre aparece como un nuevo punto de arraigo, presentes en su naturaleza y en cada individuo, cuando interrogamos ese lazo, Lefort indica que surgen tres paradojas:

Primera figura de la paradoja: la sociedad se concibe como sociedad de hombres libres e iguales, sociedad idealmente una, en este sentido, y homogénea. Sin embargo, como ya hemos dicho, más allá del enunciado de los derechos naturales y dentro de su enunciado mismo se indica una mutación esencial, pues en lo sucesivo esta sociedad muestra ser incircunscribible, ya no puede relacionarse consigo misma en todos sus elementos ni representarse como un solo cuerpo, privada como está de la mediación 
de un poder incorporado. En otros términos, quedan reconocidos modos de existencia, modos de actividad, modos de comunicación cuyos efectos son indeterminados; y, por la misma razón, ellos desbordan la órbita del poder. Segunda figura de la paradoja: los derechos del hombre están enunciados; lo están como derechos que pertenecen al hombre, pero, simultáneamente, el hombre se revela a través de sus mandatarios como aquel cuya esencia es enunciar sus derechos. Imposible separar el enunciado de la enunciación, por cuanto nadie podría ocupar el lugar, a distancia de todos, en el que tendría autoridad para otorgar o ratificar derechos- Por lo tanto, no es que simplemente los derechos sean objeto de una declaración: es de su esencia declararse. Tercera figura de la paradoja: los derechos del hombre se presentan como derechos de los individuos, y los individuos aparecen como otros tantos pequeños soberanos independientes reinando cada uno sobre su mundo privado, como otras tantas microunidades desligadas del conjunto social; pero esta representación invalida otra: la de una totalidad trascendente a sus partes. Esta representación pone de manifiesto una dimensión transversal de las relaciones sociales de las que los individuos son términos, pero que confieren a éstos su identidad al mismo tiempo que ellos mismos las producen (1990:23-24).

De estas tres paradojas Lefort extrae algunas conclusiones: si por una parte el individuo impugna la unidad y homogeneidad del poder y la sociedad, por otra parte, es productor de una heterogeneidad de relaciones sociales que muestran su interdependencia; si, por una parte, los derechos aparecen como propiedades naturales o propiedad privada, en su realidad existen como potencia performativa, en su enunciación. Y, por lo tanto, la crítica al hombre sin atributos o determinaciones dirigida al sujeto de derechos abstracto "no se disocia de lo indeterminable", donde radica la revolución política democrática. Excediendo a todo poder que pretenda determinarlos, también "su formulación contiene la exigencia de su reformulación o que los derechos están necesariamente llamados a sostener 
derechos nuevos". De esta manera, "el Estado democrático excede los límites tradicionalmente asignados al Estado de derecho. Sufre el ejercicio de derechos que todavía no tiene incorporados" (1990:24-25).

En Lefort emerge una dimensión relacional de los derechos (tanto social como performativa y, por ello, también el concepto de práctica), que cuestiona su caracterización individualista, pero el énfasis en la potencialidad democrática que portan los derechos radica fundamentalmente en mantener siembre abierta su constitutiva indeterminación, dada la indeterminación del sujeto de los derechos, lo que hace posible la revisión e institución permanente de nuevos derechos: un quién tendencialmente inclusivo porque indeterminable, a partir de un cómo democrático, en cuanto práctica política, donde "el derecho establecido queda sujeto a cuestionamiento" (Lefort, 1990:25).

Lefort sólo considera esta operación a partir de la forma que adopta la formulación de los derechos modernos, sin relevar que además los derechos son también, porque relacionales, constitutivamente plurales, y su potencialidad democrática no radica solo en su capacidad inclusiva infinita a partir de la universalidad vacía que "representan", sino también en la modificación permanente de la trama relacional que se constituye, cada vez que un derecho instituido es ampliado o nuevo derecho es enunciado. La fundamental lectura no liberal de los derechos liberales que nos propone Lefort, puede encontrar sus límites, por ejemplo, en los "derechos diferenciales", asociados a relaciones siempre determinadas y vinculados a colectivos, al establecer una relación con lo real, que Lefort se esfuerza por mantener a distancia del orden simbólico propio de los derechos.

La indeterminación lefortiana de los derechos, recupera la dinámica democrática en una pluralidad de sujetos -contemporánea a la centralidad que adquirieron los movimientos sociales en la década del 80- aunque encuentra su adhesión en las sociedades democráticas a partir de un doble reaseguro: al indicar la imposibilidad de excluir a "cualquier" individuo de un 
enunciado de derechos, y al hacerlos depender de una "conciencia de los derechos". Estos reaseguros, por una vía negativa y positiva, si bien siempre se mantienen en una tensión con su institucionalización, también tienden a restituir un sujeto individual como punto de anclaje.

Los derechos, declarados en diferentes luchas, son una pluralidad. La pluralidad es constitutiva de su propia trama material y simbólica. No presuponen su representación a priori en un sistema y su valencia política no depende de su traductibilidad en un marco legal y normativo. Su irreductibilidad a un sistema jurídico determinado no está dada -o no solamentepor el principio indeterminado que expresan, sino porque esa pluralidad se resiste a asumir un equivalente general de todos los derechos, una reductio ad unum (como el derecho a la vida, a la libertad, o cualquier otro derecho en particular) que haga posible una aritmética jurídica o política que resuelva su orden, jerarquía y relación.

Considerados en su pluralidad, cada derecho se liga con otro como los hilos de una trama cuyo tejido no tiene centro ni periferia, ni supone una relación causal necesaria. Cada derecho es un punto de intersección, una puesta en relación: al anudarse con uno y otro derecho, afecta y es afectado en su composición y sentido. Trazando vínculos no exentos de opacidades y desacuerdos, ningún derecho se mantiene incólume cuando se liga a otros. Podríamos decir que su indeterminación no radica solo en su carácter universal vacío, sino principalmente en su sobredeterminación (entre condiciones materiales y simbólicas interdependientes), en cuanto derechos relacionales. Así, cuando un "nuevo derecho" es incorporado, reconocido, incluso ya desde el plano de las luchas (previo a su modo y posibilidad de institucionalización), cambia también el conjunto de los derechos, traza nuevas relaciones, contenidos y posibilidades.

El reenvío de la conquista de derechos a su traducción como derecho-propiedad individual, propia de la tradición liberal, forma parte de una estructura de contención ante sus imprevisibles 
posibilidades. Por ejemplo, las luchas por los derechos laborales, relativas a la jornada laboral -que atravesaron el siglo XIX, XX, así como el nuestro- afecta directamente el alcance y contenido del derecho a la libertad, introduciendo una dimensión colectiva donde solo rige el derecho individual a la libre disposición de la fuerza de trabajo, pero también abre el horizonte a otros derechos, desde la salud, a la educación, la cultura, el derecho a la libre asociación, etc. Así como, a la inversa, es constatable cómo la suspensión transitoria del derecho a la libre movilidad que caracteriza la pena en el sistema carcelario, termina afectando -en algunos casos suprimiendo de hecho, en otros alterándolos sustantivamente- toda otra serie de derechos que se supone permanecen incólumes ${ }^{6}$.

\section{Entre el "derecho a tener derechos" y la dominación}

En una de sus lecturas sobre el motivo arendtiano del "derecho a tener derechos", Balibar señala que Arendt podría aproximarse al Marx de la 6ta Tesis sobre Feuerbach, al postular la condición humana a partir de la pluralidad, pero se distanciaría de Marx al separar la esfera de las relaciones naturales y necesarias de la esfera política, siendo ésta última la que hace posible el espacio público y la libertad, no determinado o mediado por la necesidad. De esta manera, y planteado en

6 En un trabajo que realizamos entre 2007 y 2009 desde un programa de la Universidad Nacional de Córdoba orientado a formación en derechos humanos para el sistema penitenciario, fue en los mismos talleres realizados con los internos que, intuitivamente, comenzó a aparecer esta dimensión relacional de los derechos, ante las limitaciones que el modelo in-formativo de la formación en derechos tiende a ofrecer. Uno de los temas discutidos allí fue, por ejemplo, de qué manera se han sostenido las demandas por el derecho al voto de los individuos privados de su libertad, y qué alcance cobra este derecho fundamental, cuando es limitado al acto electoral, pero privado del derecho a la libre participación, asociación, representación, expresión pública, libre acceso a la información, inviolabilidad de la correspondencia, derecho a la protesta, etc.; es decir, reducido a un acto de delegación del poder, sin las múltiples relaciones asociadas de manera directa o indirecta a las prácticas cívicas. Emergían así, no solo el problema de la violencia institucional y el acceso a la justicia, sino también un modo de administración del posible reconocimiento de un derecho, enmarcado en un sistema de atomización y neutralización de los derechos. 
los términos que venimos desarrollando, el espacio "entre" los hombres, la pluralidad humana (Inter homine esse) siempre se encuentra vacío de determinaciones y es lo que hace posible la libertad, que es la relación política fundante: "La política surge en el entre y se establece como relación" (1997:46).

Es en la relación política, propia de la acción concertada, donde Arendt indica que se encontraría una respuesta a la paradoja de los Derechos del hombre desarrollada en el capítulo IX de Los orígenes del totalitarismo, "La decadencia de la Nación-Estado y el final de los derechos del hombre" (1994), donde los supuestos derechos naturales, universales e inalienables, carecieron de toda existencia y eficacia, toda vez que no había un Estado para garantizarlos.

si la abolición de los derechos del ciudadano significa también la destrucción de los derechos del hombre, es porque en realidad los segundos reposan sobre los primeros y no a la inversa. Al respecto existe una razón intrínseca, inherente a la noción misma de "derechos" y a su carácter relacional, o más exactamente, a la idea de reciprocidad que les es inherente: los derechos no son "propiedades" $\mathrm{O}$ "cualidades" que los individuos poseen cada uno por cuenta propia, sino cualidades que los individuos se confieren los unos a los otros; y es precisamente por ello que se confieren los unos a los otros instituyen un "mundo común" en el que éstos pueden ser considerados responsables de sus acciones y opiniones. Ahí estriba la importancia crucial que adquiere la fórmula "derecho a tener derechos": el derecho a tener derechos es precisamente aquello de lo que son privados los «sin Estado» y más generalmente los individuos y los grupos de excluidos que se multiplican en las sociedades contemporáneas. Y entre los derechos de los que son privados los individuos, debemos incluir el derecho polí tico fundamental de exigir o de reivindicar sus derechos, o el «derecho de petición» en el sentido de la época clásica. La tesis recíproca que se deriva, es que el derecho "primero" es justamente el "derecho a tener derechos", 
tomado absolutamente, o en su indeterminación [...], y en ningún caso un derecho "estatutario" particular. En este sentido, se trata de un derecho sin fundamento $a$ priori, tan contingente como lo es la comunidad política ella-misma, o más precisamente, la existencia de una comunidad de acciones politicas, un compromiso simultáneo de los individuos en la acción política común (Balibar, 2007:92-93).

De los varios elementos presentes en el análisis (que se multiplican a lo largo de todo el texto), quisiera tomar uno, ligado al carácter relacional de la noción de derechos, que Balibar denomina "reciprocidad" y que bien podría ser leído en términos de reconocimiento. Porque, como venimos sosteniendo, si los derechos no son propiedades naturales, pero tampoco propiedades formales dependientes de la representación estatal, tener un derecho no significa otra cosa que establecer una relación de mutua y necesaria atribución. Nada hay menos individual que un derecho, puesto que solo existe en su reconocimiento por otro, que a su vez y por ello es recíprocamente reconocido. Podríamos decir también que la performatividad indicada por Lefort sobre el carácter declarativo de los derechos opera aquí horizontalmente, y por tanto los derechos son primariamente una relación que solo es posible entre los individuos, instituyendo un espacio común. De acuerdo a Balibar, para Arendt "con rigor, se debería afirmar que los seres humanos "son sus derechos", o existen por o a través de ellos" (2007:94), en un sentido que vuelve sobre la proximidad con 6ta tesis marxiana.

Sin embargo, el "derecho a tener derechos", en cuanto "derecho político fundamental", primero en relación a cualquier otro, indeterminado en su contenido, pero determinante de la constitución del espacio político que hace posible los derechos, reproduce la diferencia ontológica entre una pluralidad como condición de la libertad y una pluralidad derivada o equivalente al carácter relacional de la condición humana: al conjunto de las relaciones sociales (en los términos de Marx). Si no escindimos una de otra, es en cada demanda de derechos y sólo en esa 
demanda donde cobra existencia el derecho a tener derechos, puesto que el derecho como relación, como dimensión que se da "entre" los individuos, no es un espacio vacío que hace posible la libertad y, por ella, los derechos, sino un espacio saturado por múltiples relaciones, en las que los derechos interfieren produciendo una alteración, tanto en su novedad, como en su trama ${ }^{7}$.

Podríamos afirmar que quienes luchan por derechos, no luchan primariamente por una inscripción individual institucional/legal, para modificar su condición de sujetos excluidos e ingresar al universal abstracto de la ciudadanía plena: luchan para erradicar una condición de desigualdad, una asimetría, una relación de dominación o sujeción que consideran injusta, discriminatoria, agraviante, y que los tiene a "ellos" sometidos. Para los "nadie" de un sistema jurídico, político y cultural determinado, no es precisamente por la afirmación de sus propiedades compartidas con otros que pueden ser portadores de derechos. Su universalización tiene su eficacia no en el inicial "todos" positivo que supone una propiedad común, pero tampoco en un "todos" indeterminado, sino en la desposesión que delata su ausencia y desencadena su eficacia política y social. Con Rancière, podría afirmarse que "Los derechos del hombre son los derechos de aquellos que no tienen los derechos que tienen y que tienen los derechos que no tienen" (2011:13), para marcar un desplazamiento que, sin embargo, siempre tensa una condición, una ausencia de condición y un desacuerdo sobre las "condiciones para": los nadie sujetos a relaciones asimétricas, que sostienen que ninguno pueda ser sometido, intervienen en una relación dada, de la que socialmente participan solo algunos, para impugnar las condiciones (que pueden ser negativas, por carencia de, o positivas, por lo que son: porque no hay solo una lógica de la exclusión) a partir de las cuales esa relación es autonomizada y aislada de lo común.

\footnotetext{
7 Una vía posible para explorar los alcances del concepto de relación, en la interdependencia entre condiciones materiales de existencia y de reconocimiento, se encuentra en la tesis de lanina Moretti Basso (2020), a partir del concepto de "materialismo performativo" que nos propone para leer a Judith Butler.
} 
Lo inmediatamente dado en el plano de los derechos -lo que remite a una o más relaciones concretas-, es que operan como índices de relaciones de dominación, de opresión, de exclusión, y su enunciación permite arrancar esas relaciones del oscuro espacio de las infinitas relaciones humanas particularizadas, para visibilizarlas como relaciones sociales y elevarlas al plano de un conflicto político; esto es, no un desacuerdo entre particulares (ni falta moral, ni contractual) sino entre partes, que se constituyen de acuerdo a las maneras en que el desacuerdo opera como demarcación de un conflicto. Los derechos son índices de una partición del orden de lo social y del orden de lo institucional. Emergen como "experiencia social de lo (in)justo" (Abdo Ferez, 2016-2017) y es allí donde se trazan las primeras formas del reconocimiento -en el uno a otro señalado por Balibar-, pero su enunciado va dirigido al conjunto de la sociedad, puesto que lo que es cuestionado no es una falta individual sino la injusticia de una relación estructurante de la sociedad. Esa dirección es polémica o agonista: entre la unidad y homogeneidad del cuerpo social que se le atribuye a una política de los derechos y los antagonismos que la enunciación de los derechos pone como marcas constitutivas de lo social -entra la unidad y la división-, emerge el hecho de que los derechos son siempre "derechos en los otros", en el sentido en que implican una atribución, un reenvío a otro, un modo de reconocimiento. Los derechos operan entre la unidad y la división, e introducen un diferendo entre un derecho y un privilegio o, en los términos que lo venimos desarrollando, una relación y no una propiedad o status.

Los derechos no son universales, como bien señala Arendt, pero son universalizables, entendiendo con ello un movimiento, un desplazamiento, no un telos ni una realización: lo son porque siempre es una parte la que, con su declaración,

8 Como se sigue del desarrollo, el concepto de relación siempre implica a otros, por lo que entendemos que la expresión "en otros" es más pertinente que la -sin duda interesante, pero ambigua- expresión "del otro", que en diferentes sentidos es utilizada por Lyotard (1993) y Benhabib (2005). 
expone un conflicto, determina una división y demanda a la comunidad pronunciarse sobre ella. Ese pronunciamiento es el reconocimiento de un derecho común a partir de la politización de un conflicto, llevado desde el desacuerdo en donde se constituyen las partes a la institución de un bien común. La pregunta no es, por ello, qué derecho es o no universal, qué enunciación pasa la prueba normativa de su universalización (incluso si éste puede formularse como "el derecho a tener derechos"9); la cuestión trata de declarar un conflicto como asunto común, trata de politizar un conflicto como nudo en donde se pone en juego el reconocimiento de un derecho como parte de la trama de relaciones que llamamos sociedad. Su movimiento hacia la universalización no es una tendencial disolución de su conflictividad, aunque siempre corre el riesgo de producir la borradura de su politicidad, la huella de su origen, principalmente por su reenvío normativo al individuo. Sin embargo, la universalidad no puede ocultar su carácter histórico y coyuntural, no deja de exponer su inevitable extensión material y las fronteras de su alcance: la universalización es inevitablemente polémica. Por eso, la tensión no se da sólo ni exclusivamente entre particular y universal, sino entre una lógica universalista y una conflictualista.

El conflicto por los derechos y su carácter polémico no puede ser reducido a una tensión o "contradicción" entre derechos diferentes que un individuo hace valer ante otro, reclamando una prerrogativa (como suele ejemplificarse en situaciones donde se visibilizan los conflictos de intereses en la sociedad), que podría ser resuelta bajo una lógica del reparto. Lo interesante aquí, en términos políticos, es cuando se produce una tensión entre un derecho y una ausencia de derecho, entre quien protege un derecho adquirido y quien reclama un derecho a ser reconocido. Si es posible que se establezcan relaciones de fuerza entre lo

9 Por eso, consideramos poco productiva la discusión sobre esta expresión arendtiana, cuando se interroga si su estatus es ontológico, moral o formal (Benhabib, 2005; Birmingham, 2017; entre otros), cuando -como es la vía emprendida por Balibar- lo que está en discusión es la politicidad de los derechos, no su "fundamento". 
existente y lo no existente, es porque uno y otro inscriben su contienda en el conjunto de las relaciones sociales. La positividad de los derechos es uno de los modos en que se dan esas relaciones, pero no la única. El poder de uno y otro depende de la capacidad que tenga para afectar un conjunto más amplio de relaciones: los derechos ponen a lo dado y lo que podría ser de otro modo en un mismo plano de lo real. Por ello, no solo no es necesario reducir los derechos a la positividad de los intereses para poder dar cuenta de la conflictividad que establecen en la sociedad, tampoco es posible circunscribirlos a un modo de relación cuando, como hemos sostenido, pueden implicar al conjunto de las relaciones, en la medida en que es imposible establecer a priori el perímetro de su alcance.

\section{5. ¿Sujeto de derechos?}

Sujeto natural, formal, o histórico, individual, colectivo o universal, son algunas de las tantas formulaciones que atraviesan la pregunta por el sujeto de los derechos y que, entre otros efectos, reproducen y justifican jerarquías normativas entre derechos, en un orden que no es extraño que esté acompañado por una conexión entre la antropología y la filosofía de la historia: hablar de tales o cuales derechos civiles, políticos, económicos, sociales, culturales, supone, más que una categorización, una jerarquía, un orden y un desenvolvimiento histórico causal y necesario. Se trata de un sujeto de derecho que parece contener en sí ya su universalidad plena, aunque carezca de una realización histórica -puesto lo que siempre falta es la incorporación progresiva de individuos concretos, del particular en el universal, del individuo en el género común a todos. El problema no estaría, desde esta perspectiva, en el modo en que pensamos los derechos, sino en su concreción, por la permanente intervención de fuerzas que le son extrínsecas y accidentales: déficits institucionales, recursos materiales limitados, prejuicios identitarios, ausencia de un espacio público, diagnósticos generales que coinciden con la descripciones particulares de las 
sociedades poco desarrolladas (dimención histórico-descriptivo de la "sinécdoque del universal", donde la parte que ha sido tomada como el todo, construye por medio de su plenitud su negativo, para designar una particularidad que todavía no puede alcanzar la universalidad).

Al final de Ciudadano sujeto, Etienne Balibar se interroga:

¿Qué decir de un sujeto que no sería solamente sujeto "de una" relación (sometido), o colocado por la experiencia, la vida, la historia, la institución "en" una relación o un conjunto de relaciones, sino que sería "como tal" relación, expuesto a los efectos de cambio de la relación que, siempre ya, lo constituye, y como tomado al inverso por su desigualdad intrínseca? (2014:331).

La pregunta no se coloca al final de la deconstrucción del sujeto. No llega después del sujeto. Hace posible insistir en la pregunta por quién es el sujeto de los derechos -como también la formulara Rancière-, no solo orientando la pregunta que una teoría crítica dirige incisivamente al concepto de sujeto, también restituyendo la centralidad que adquiere el "quién", en su materialidad concreta, donde se anudan las condiciones materiales de existencia y de reconocimiento, su inter-dependencia, para poder dirigirnos al concepto de derechos desde otra perspectiva, y situar la pregunta en el presente. Porque no se trata de examinar qué es lo que podrían los derechos si..., reenviándolos a un plano ideal que adquiere la temporalidad de un aplazamiento, sino abordarlos a partir de lo que pueden.

Pensar los derechos como relación, con nosotros mismos, con los otros y con el mundo (lo que incluye, también, a las futuras generaciones), en su pluralidad, conflictividad, disputabilidad, pero también interdependencia, abierta a una permanente transformación (que, como tal, puede ser emancipatoria, aunque también conservadora, porque, como bien afirma Tilly, los derechos se conquistan pero también se pierden), permite identificar los límites que una concepción del sujeto la impone a una política de los derechos. Pensar una ontología social de 
los derechos, posibilita dar otro alcance a los modos en que, en diferentes lugares, cobran las luchas por los derechos y se amplían los modos de imaginarlos.

Si podemos afirmar que, considerando un derecho relacional, todos los derechos son derechos sociales, las luchas por los derechos en Latinoamérica, así como las diferentes apuestas políticas por su institucionalización, nos presentan una escena donde las necesidades y las libertades, las condiciones materiales de existencia y de reconocimiento, no pueden ajustarse a orden causal y necesario, impuesto por la matriz dualista que, en sus diversas variantes, comparten las teorías del sujeto. La relación, la implicación recíproca, trazan una nueva territorialidad y se desarrollan en un horizonte -no libre de tensiones-, que nos permite revisar la supuesta irresoluble paradoja entre lo individual y lo común, así como también encadenar derechos que, a partir de esa misma paradoja, son presentados como derechos de naturaleza diversa y, por ello, jerarquizados (moralmente, políticamente y epistémicamente) y distribuidos en espacios y tiempos diferenciados, de acuerdo a lógicas que -según esta concepción- debieran serles extrínsecas: clases, razas, géneros, nacionalidades, son también productos del universalismo occidental.

Pues no hay individuo por fuera de un conjunto de relaciones o, más aún, no hay individuo sino como relación, de igual manera que no hay una identidad genérica común, sino como un conjunto o una totalidad siempre abierta de relaciones. Las implicancias de esta tesis pueden dar cuenta, bajo otra perspectiva, de la génesis a-teleológica y plural de los modos de ser-ciudadano de acuerdo a las diferentes relaciones que van constituyendo los cuerpos y las subjetividades individuales y colectivas, las formas de organización, de aparición en el espacio público y "privado", de ser representados por la ley, de la institución de lenguajes políticos, así como también en las formas de interpelación estatal (que se valen o no, y de qué manera, de los derechos para formular políticas públicas, producir reformas estatales, confrontar a los poderes privados, 
etc.). En este terreno, las luchas por los derechos y las políticas públicas orientadas a derechos -donde se producen desacuerdos y encuentros- han formulado, en lo que podríamos denominar derechos diferenciales, no tanto un medio para alcanzar una ciudadanía homogénea (aunque ese discurso todavía tiene una pregnancia considerable), como un modo de intervenir en relaciones sociales asimétricas, generando un espacio polémico entre ciudadanos y no-ciudadanos, y promoviendo modos de reconocimiento donde la no-ciudadanía genera atomización y aislamiento. Preguntarse sobre si hay una prioridad de los derechos políticos por sobre los derechos sociales o a la inversa, es introducir una causalidad donde hay una trama plural de relaciones, es también introducir una antropología de la necesidad y la libertad, de la pasividad y la actividad, donde hay una conflictividad que es inmanente a los derechos, cada vez que tocan una relación de asimetría, de dominación, de exclusión, desapropiándola de sus cualidades naturales e históricamente aceptadas. Este es uno de los motivos por los que, particularmente en Latinoamérica, el conservadurismo liberal encuentra en las luchas por los derechos y su acogida por parte de los gobiernos democráticos populares, un motivo de discordia y la imposibilidad de apropiarse de una gramática que, por lo menos en términos teóricos, pero también como dispositivo de normalización social, les ha sido propia y resulta cara a "su" tradición.

Sea que analicemos políticas como el "matrimonio igualitario", la "Asignación universal por hijo" (o la "Bolsa Familia", en Brasil), o incluso una política más puntual, como el reconocimiento de la relación laboral de las empleadas domésticas, todas planteadas como derechos, lo que encontramos es la afectación de una trama compleja y plural de relaciones sociales invisibilizadas. En ese último caso que mencionamos, donde no había, ni más ni menos que, una ampliación hacia una actividad poco regulada de un derecho existente, podemos ver en ese más, las relaciones afectadas: relaciones laborales de servidumbre, actividades generizadas, contratos heterodoxos e intercambio 
de salario por otros bienes, inclusión en lazos familiares afectivamente jerarquizados y discrecionales, invisibilización de la "casa" como espacio privado y privatizado (que se extiende a otros espacios, como salidas vacacionales, festejos, etc.), racialización, extranjerización, lenguajes eufemísticos y tradicionales que describen la labor ("la chica que viene a casa", "la chica que me ayuda", "la sirvienta", "criada", etc.), visibilización de las tareas de cuidado. Éstas y otras relaciones que se encadenan unas a otras a partir de un derecho que, aunque circunscripto a la relación laboral contractual, afecta toda una trama ligada también a otros derechos existentes, a derechos no institucionalizados cuyas demandas se encuentran en la escena pública e incluso a derechos todavía no imaginados (así como afecta la matrices que estructuran la política, como la división público-privado, que es aquí interferida en un espacio paradigmático como es la "casa" o posibilitan modos del reconocimiento, por ejemplo, en los tantos filones compartidos con las plurales luchas de los feminismos contemporáneos). Como pude verse, condiciones materiales de existencia y de reconocimiento se anudan y se multiplican para producir alteraciones en la relación con nosotros mismos, con los otros y con el mundo (las instituciones, la cultura). Consientes también, y por los mismos motivos, que un reconocimiento institucionalizado como el descripto produce conflictos, rechazos y bloqueos, justamente porque también se inscribe en otras relaciones que se le contraponen de manera directa o indirecta. Lo que sí queda claro es que hay una diferencia entre encontrarse y no encontrarse en una relación de derechos.

Los efectos de una política de los derechos escapan a toda previsión, porque la alteración de un hilo de la trama, es la alteración de un entramado más amplio. Más aún si los derechos, siempre considerados en plural y no como un encadenamiento normativo, establecen composiciones entre sí, que transgreden los formalismos que suelen agruparlos según su naturaleza o tipo. En las luchas por los derechos, los derechos catalogados como civiles, políticos, económicos y laborales, sexo-genéricos, 
culturales, etc., se conectan entre sí modificando los sentidos de cada uno considerado aisladamente y, por extensión, transgreden la frontera de su atribución, sea al individuo, sea a un colectivo, sea al pueblo (volviendo a Balibar, son individuales porque colectivos), en la medida en que no siguen la lógica de lo más particular a lo más general, sino que extienden, comunican y contaminan las fronteras en donde las individualidades e identidades tienden a cerrarse. Que los derechos, considerados como relación, no sean propiedades ni de los individuos, ni de los colectivos, ni del Estado, muestran lo impropio de toda apropiación, y la imposibilidad de establecer un control sobre sus efectos.

Es desde este marco que podemos leer la política de ampliación de derechos -una de las denominaciones que ha adquirido más centralidad en el siglo XXI Latinoamericanono como una adición de bienes particulares que se acumula cuantitativamente, como predicados de un sujeto cada vez más nutrido de prerrogativas, sino como una permanente transformación cualitativa del conjunto de los derechos, que pone en juego nuestros modos de habitar un mundo-compartido y disputan una idea de sociedad, como parte de un momento de politización democrática. Mientras más derechos se liguen entre sí, más potencia social y poder institucional tendrá su declaración, práctica y eficacia. Insistir en afirmar cualidades esenciales o formales de los derechos los sustrae de una trama relacional que hace posible su politicidad, y la posibilidad de una reinvención permanente e infinita en sus posibilidades. Pero también, y esto forma parte de nuestra experiencia más inmediata, una reorganización de los poderes de facto, cuyas posiciones encuentran en la denominación "anti-derechos" una clave de interpretación tan acertada como las de neoconservadurismo o neoliberalismo. 


\section{Bibliografía}

Abdo Ferez, C (2013) Crimen y sí mismo. La conformación del individuo en la temprana modernidad occidental. Buenos Aires: Gorla.

Abdo Ferez, C (2016-2017) La experiencia social de lo (in)justo. Revisitando concepciones de derechos para América Latina contemporánea. POSTData, 26, número 2, octubre-marzo.

Arendt, H (1994) Los orígenes del totalitarismo. Barcelona: Planeta-Agostini.

Arendt, H (1997) ¿Qué es la política? Barcelona: Paidos.

Balibar, E. (2000). La filosofía de Marx. Buenos Aires: Nueva Visión.

Balibar, E. (2007) La impolítica de los derechos humanos. Arendt: el derecho a tener derechos y la desobediencia cívica. Erytheis, número 2 , noviembre.

Balibar, E (2009) De la individualidad a la transindividualidad. Córdoba: Encuentro Grupo Editor.

Balibar, E. (2014). Ciudadano sujeto. Vol. 2: Ensayos de antropología política. Buenos Aires: Prometeo.

Benhabib, S (2005) «El derecho a tener derechos»: Hannah Arendt y las contradicciones del Estado-Nación. En Los derechos de los otros. Barcelona: Gedisa.

Birmingham, P (2017) Hannah Arendt y los derechos humanos: el dilema de la responsabilidad común. Buenos Aires: Prometeo.

Brown, W (2007) Lo que se pierde con los derechos. En Brown, W. y Willians, P. La crítica de los derechos. Bogotá: Siglo del Hombre.

Foucault, M. (2007) El nacimiento de la biopolítica. Buenos Aires: Fondo de Cultura Económica.

Foucault, M. (2006) Defender la sociedad. Buenos Aires: Fondo de Cultura Económica.

Foucault, M. (1994) Le triomphe social du plaisir sexuel: une conversation avec Michel Foucault. En Dits et Ecrits IV 1980-1988. Paris: Gallimard.

Lefort, C. (1990) "Derechos del hombre y política". En La invención democrática. Buenos Aires: Nueva Visión. 
Lyotard, J-F (1993) The other's rights. En Shute S. y Hurley, S. (eds.), On Human Rights.The Oxford Amnesty Lectures. New York: Basic Books-Harper Collins Publishers.

Monge, J (2018), Política de la verdad, filosofía y formas de vida en Foucault: de Nietzsche a un nuevo materialismo. Universidad Nacional de Córdoba: Tesis inédita.

Moretti Basso, I (2020). Cuerpos y Alianzas. Un estudio butleriano sobre las posibilidades performativas de la agencia ante la violencia normativa. Universidad Nacional de Córdoba: Tesis inédita.

Morfino, V (2010) Spinoza. Relación y contingencia. Córdoba: Encuentro Grupo Editor.

Morfino, V (2014) El tiempo de la multitud. Madrid: Tierradenadie ediciones.

Negri, A (1993) Anomalía salvaje. México: Anthropos.

Negri, A (2000) Spinoza subversivo. Madrid: Akal.

Ranciére, J (2011) “Quién es el sujeto de los derechos humanos?”. Derecho y barbarie, $\mathrm{n}^{\circ} 3$.

Rinesi, E (2015) Filosofía (y) política de la universidad. Los Polvorines: IEC-UNGS.

Tilly, Ch. (2004). ¿De dónde viene los derechos? Sociológica, año 19, número 55, mayo-agosto.

Žižek, S (2011). Contra los derechos humanos. Suma de negocios, Vol. $2, \mathrm{n}^{\circ} 2$, diciembre. 